\title{
Correction of elderly age people's psycho-physiological condition by recreation motor activity
}

\author{
Mytskan B.M. ${ }^{1}$, Cynarski W. ${ }^{2}$, Fedoryuk A.V. ${ }^{3}$, Popel' S.L. ${ }^{1}$, Mytskan T.S. ${ }^{1}$, Zemska N.O. ${ }^{1}$ \\ ${ }^{1}$ Vasyl Stefanyk Precarpathian National University \\ ${ }^{2}$ University of Rzeszów, Poland \\ ${ }^{3}$ Ivano-Frankivsk National Medical University
}

\begin{abstract}
Purpose:

to work out program of elderly age people's psycho-physiological condition correction by recreation-motor activity and test its effectiveness.

Material: $\quad$ psycho-physiological condition and life quality of 50-65 years' age 155 teachers were analyzed with the help of two questionnaires. 50 teachers with low level of recreation activity were selected and divided into control and experimental group ( 25 persons in each).

Results: $\quad$ main problems in organization of physical recreation have been determined. It became a base for working out and substantiation measures for intensification recreation activity of elderly age teachers. The basic principles of the worked out program are as follows: all year round physical exercises in natural geographicclimatic conditions; teachers' distribution by groups of recreation activity and level of motor activity.

Conclusions: we have proved effectiveness of the offered measures, in respect of elderly age teachers' sleep and psychophysiological state improvement.

Keywords: $\quad$ teacher, psycho-physiological state, sleep, recreation activity, elderly age.
\end{abstract}

\section{Introduction}

Demographic researches' data $[3,5,9]$ witness about constant increase of working elderly people in general structure of population. As on to day it is rather complex sociological and medical-psychological problem. That is why there appears a demand in comprehensive study of ageing processes $[1,12,13,22]$ and physical recreation means $[8,11,19]$, permitting to sustain proper level of psycho-physiological condition (PPC). Intensification of recreation activity (RA) is the base of such level.

In some works $[1,2,3,16,21]$ it is proved that in higher educational establishments there is deficit of RA. Especially it concerns elderly age teachers (EAT). Such situation formed as a result of low competence and motivation, i.e.: absence of creeds about need in supporting own PPC at high level; ignoring the most effective health related recreation means $[4,7,14]$.

The existing approaches to health related measures' realization at higher educational establishments (HEE) are rather ineffective [5, 7]. As a result it weakens interest to physical culture and makes impossible prioritizing of recreation motor activity $[11,14,19]$.

The woks by H.W. Robert et al. [23] proved that most people in 50-65 years age have certain syndromes of chronic fatigue with expressed signs of sleep disorders. In system of recreation measures sleep is considered as basic rest $[14,20,22]$. Without proper sleep recreation motor measures can result in adaptation mechanisms' failure and symptoms of diseases [17, 18, 19].

Theoretical study of the mentioned problem proves that in to-day's conditions physical recreation is based on well grounded, legal support. It is oriented on solution of the following tasks: organization of leisure; recreation of psycho-physical workability; compensation of motor (C) Mytskan B.M., Cynarski W., Fedoryuk A.V., Popel' S.L.,

Mytskan T.S., Zemska N.O., 2017

doi:10.15561/18189172.2017.0107 deficit, conditioned by professional specifics; preservation of organism's functional reserves (as the base of somatic health); satisfaction of demand in health related way of life $[7,15]$.

Recent years there have been appeared a lot of scientific works [1, 2, 13, 15, 16], devoted to PPC strengthening by means of physical culture. However, influence of RA on psycho-physiological condition of persons, engaged in teaching at HEEs has not been elucidated sufficiently in scientific literature. So it requires further studies.

Hypothesis: it is assumed that recreation of motor activity influences positively on quality of basic rest (sleep) and psycho-physiological state of elderly teachers, having low recreation activity level.

The purpose of the work is to work out program of elderly age people's psycho-physiological condition correction by recreation-motor activity and test its effectiveness.

\section{Material and methods}

Participants: the study was conducted in HEE (Ivano-Frankovsk) in the period from 2012 to 2015. In the research 155 persons participated (women $n=71$; men $n=84$; age 50-65years). From them we selected 50 teachers with low RA. They were divided into control $(C G, n=25)$ and experimental (EG, $n=25)$ groups.

Organization of the research: in the research we used test-questionnaire for assessment of self-feeling, activity and mood by G.L. Apanasenko's methodic [6]. We analyzed somatic health level also by methodic of G.L. Apanasenko [10]. Besides, questionnaires for determination of sleep subjective character was used (questionnaires "If you have insomnia" and "Healthy sleep”). For objective assessment we used EEG “Tredex" (Ukraine). Spectral analysis of heart rhythm variability $(\mathrm{CardioLab}+)$ was fulfilled. Besides, we determined 
quantitative and qualitative characteristics of motor activity by Framingham methodic.

For assessment of teachers' readiness for RA intensification we worked out diagnostic methodic for finding different components by the following formula:

$$
\mathrm{PC}_{(\mathrm{RA})}=\mathrm{CC}+\mathrm{EMC}+\mathrm{WC}+\mathrm{BC} \text {, }
$$

where $\mathrm{PC}_{(\mathrm{RKA})}$ - personal competence concerning RA; CC - cognitive component; EMC - emotional-motivation component; WC- will component; BC - behavioral component.

Each indicator was assessed by criteria of presence and expression by scale: from 1 to 3 points - low level; 4-6 points - average level; 7-9 points - high RA level.

In CG recreational measures were realized in free time as non-organized leisure as per own potentials and wishes.

In EG measures on RA intensification were realized as per worked out program. The program realization required one calendar year, divided in four stages: preparatoryadaptive, training, supporting and finalizing.

Preparatory-adaptive stage took 6 weeks and was realized at threshold of physical loads' intensity. The main tasks implied the following: formation teachers' personal competence in RA intensification; adaptation of heart-vascular and respiratory systems to physical loads; reduction of psychological tension and creation optimistic attitude and belief in own potentials; organism's hardening.

The second (training) stage took five months. It corresponded to physical loads of average intensity. The tasks of this stage were: strengthening of organism's physiological systems functioning; improvement of psycho-emotional state; improvement of organism's adaptation potentials.

The third, supporting, stage took five months. The trainings ere conducted with moderate intensity. The main tasks of this stage were: further expansion of recreation-motor activity and preservation of the achieved physical and mental workability level; strengthening of general endurance; correction of psycho-emotional state; improvement of sleep quality.

The forth finalizing stage took 2 weeks. This stage measures were realized in sport-health recreational camp in conditions of middle altitude. The main tasks of this stage were: preservation of the achieved level of recreation motor activity and sleep quality improvement. For improvement of night sleep quality characteristics in finalizing stage the teachers were offered to take oxygen cocktail with different phyto-fillers (day norm -2 portions; one of them shall be taken 20-30 minute before sleep[; other - by wish, during day).

Load control by indicators of maximal, peak and threshold heart beats rate (HBR) was realized with the following formulas:

$$
\begin{aligned}
& \mathrm{HBR}_{\text {max }}=220-\text { age }(\text { in years }) ; \\
& \text { HBR bottom limit }=220-\text { age } \times 0.6 \text {; } \\
& \text { HBR top limit }=220-\text { age } \times 0.75 .
\end{aligned}
$$

The program stipulates:

- Morning exercises (correcting, different kinds of general gymnastic exercises; in motion, with objects, in pairs, in circle, on stimulators, jumps, walk, run, breathing exercises). Morning exercises are fulfilled independently, during 10-15 minutes;

- Hardening (cold shower, rubbing, walk barefoot, sun and air baths). The procedures are fulfilled independently, during 15-25 minutes;

- Outdoor games for motor abilities (with elements of run, jumps, throws; overcoming resistance, coordination, attention, memory and moral-will qualities). They shall be fulfilled independently or under supervision of specialists during 1-2 hours;

- Health related, recreation swimming shall be fulfilled independently or under supervision of specialist: 1-2 times a week, during 15-20 minutes;

- Health-run (jogging with compulsory shin muscles' warming; duration - 30-45 minutes. To be fulfilled independently or under supervision of specialist;

- Training in sport circles (adapted for age - mini football, volleyball, basketball, ping-pong, badminton). To be fulfilled independently or under supervision of specialist, duration 45-90 minutes;

- Hiking, excursions and walks (independent or under supervision of specialists with different outdoor games in he nature) shall take from 1 to 3 hours, during 1-2 days;

- Dancing exercises: shall be fulfilled independently or under supervision of specialist 1-3 time a week and take 45-60 minutes. Load intensity shall be 90-110 bpm, depending on kind of training.

Effectiveness of the offered program was tested by repeated assessment of EG and CG teachers' recreation activity and psycho-physiological state.

Statistical analysis implied data processing with the help of parametric and non-parametric methods of statistic.

\section{Results}

The fulfilled study showed that with age portion of teachers, who are not satisfied with own psychophysiological state, increases $(r=-0.38 ; p<0.05)$. Life quality is negatively influenced by the following factors: watching TV for long time $\left(r_{s}=0.38 ; p<0.05\right)$; low readiness for recreation motor activity $\left(r_{s}=0.42 ; p<0.05\right)$; chronic diseases $\left(\chi^{2}=25.5 ; p<0.01\right)$; hobby, requiring immobile means of realization $\left(r_{s}=0.44 ; p<0.05\right)$; loneliness and domestic conditions $\left(\chi^{2}=29.4 ; p<0.01\right)$. Among the most negative factors of life quality the following should be noted: low motor activity $-37.6 \pm 6.24 \%$; irrational eating $-29.8 \pm 3.12 \%$; taking alcohol $-50.4 \pm 4.36 \%$ and tobacco smoking $-19.5 \pm 1.83 \%$.

It was found that most $(84.8 \pm 2.55 \%)$ of teachers want to receive recreational services in the form of group and individual trainings under supervision of instructor or with the help of trade union functionaries or sport clubs. It points at demand in application of scientifically substantiated, accessible physical recreation system for 
teachers through the mentioned public organizations.

It was found that $63.2 \%$ of teachers do not practice physical recreation at all, $22.7 \%$ practice it from time to time. Own RA level is assessed as "low" nearly by two third of the questioned (74.8\%).

Analysis of teachers' readiness for RA intensification showed its low level (48.4\%). In 52.3\% of teachers it closely correlates with low PPC level. It demands application of health related recreation measures.

Assessment of stating experiment results shows that $57.4 \%$ of respondents had low and below average levels of personal competence in RA. It was found that no teacher had high RA competence. Nearly $90.0 \%$ of day time they are in static position. Only 2.9\% teachers had high motor activity level. Such situation is a result of the following: low readiness for RA ( $\mathrm{r}=0.87)$; excessive body weight (in $78.9 \%$ of men and in $89.3 \%$ of women). It is witnessed by indicators of body weight (higher than 30.0).

We also found great quantity of persons (95.8\%) with sleep disorders of different character and expressiveness. As Ye.N. Prystupa points [14] sleep ensures basic rest and facilitates adaptation to psycho-emotional stresses at low cost. Sleep plays important role in mechanisms of psychological defense in professional functioning [18].

The main EEG signs of sleep disorders are the following: periodic delay of background activity and main rhythm; simple partial attacks with motor symptoms; quick delta oscillations with high amplitude like outburst of slow activity in frontal lobe. The found electric neurographic changes can serve as objective base for assessment of recreational programs' effectiveness for elderly people.

The conducted complex research of PPC and physical recreation's organization among teachers permitted to determine the main problems and work out programs of RA optimization and PPC correction by physical recreation means.

This program contains new and improved functionalstructural elements.

In the offered program the objects of control is the process of physical recreation and the subject of control psycho-physiological state of 50-65 years' persons. років. Block of informational provisioning ensured formation of teachers' with low RA register, who require physical recreation.

The main tasks of the offered program implementation is improvement of recreation servicing of HEE teachers staff (integration and coordination of work between higher educational establishments' administration, their trade unions and sport clubs as well as centers of population's social support; improvement of physical recreation measures; study of low RA reasons; finding of persons, requiring physical recreation).

By results of formation experiment, in EG we registered confidently $(p<0.05)$ higher $R A$ and all its components. With it, high RA level was achieved by $73.3 \%$ persons, average - by $26.7 \%$. In no teacher we found low level.

Teachers' participation in program of RA correction resulted in confident $(\mathrm{p}<0.05)$ improvement of personal attitude to PPC, which corresponded to high level in $54.0 \pm 5.12 \%$ of teachers. By $65.2 \pm 7.44 \%$ indicator of ability to plan personal RA increased. At the same time, quantity of persons with high and average day motor activity raised (accordingly by $5.0 \%$ and 13.1\%). It positively influenced on index of day physical activity (37.5 points, $\mathrm{p}<0.05$ ).

Correlation analysis permitted to determine direct dependence between RA and somatic health (SH). High $\mathrm{SH}$ level was found in $9.1 \%$ of men and in $4.3 \%$ of women in EG. Besides, confidently higher was portion of persons with average and above average levels (accordingly in $23.1 \%$ and $12.9 \%$ cases, $\mathrm{p}<0.05$ ). RA level increased by $53.4 \%$; integral coefficient of physical recreation effectiveness raised up to $59.7 \%$; teachers' knowledge about use of physical exercises in the nature increased 2.8 times $(\mathrm{p}<0.05)$. It should be noted that before pedagogic experiment teachers had average level of different components of readiness for recreation-motor activity (see table 1).

Table 1. Integral assessment of 55-60 age teachers' psycho-physiological condition before and after application of health related recreation program $(n=50$, points)

\begin{tabular}{lll}
\hline Indicators & CG & EG \\
\hline Emotional readiness & $3.9 \pm 024$ & $4.5 \pm 0.25^{*}$ \\
Psycho-motor readiness & $3.7 \pm 0.12$ & $4.8 \pm 0.14^{*}$ \\
Regulatory readiness & $3.7 \pm 0.35$ & $4.4 \pm 0.26^{*}$ \\
\hline
\end{tabular}

Note:* $-p<0.05$ comparing with CG.

Implementation of health-related recreational program resulted in confident $(\mathrm{p}<0.05)$ increase of psycho-motor readiness indicators - by $26.3 \%$, emotional - by $18.4 \%$ and regulatory - by $18.9 \%$ (see table 1 ). In the course of pedagogic experiment PPC increased in $42.1 \%$ of men and $45.2 \%$ of women. Body weight index dropped by $34.2 \%$ in men and by $28.9 \%$ in women. Stress resistance increased (accordingly by $54.6 \%$ and $49.8 \%$ ). Questionnaire "Healthy sleep" and EEG indicators showed normalization of sleep.

It is illustrated by renewal of main waves' amplitudefrequency characteristics (in $45.2 \pm 2.44 \%$ cases) and sleep stabilization (in $64.1 \pm 2.19 \%$ cases).

\section{Discussion}

We can state that the problem of psycho-physiological condition correction by physical recreation means has been remaining unstudied and requires further theoretical studying, scientific analysis and appropriate organizational methodic provisioning $[3,5,6]$. Results of our research are proved by the data of other authors [7, 8, 12, 16, 19]. With it, high interest of teachers to physical recreation is observed [13, 15]. Alongside with it, accessible means of its realization have relatively low effectiveness [12, 20] and day regime organization is irrational. It conditions psycho-physiological condition's worsening [9]. 
Our results are in agreement with the data of many authors [1, 2, 3] and point that most of teachers in 5065 age have different symptoms of chronic fatigue with sleep disorders. Researches $[9,10]$ proved that in system of recreation measures sleep is regarded as basic rest. Without full-fledged sleep recreation measures can result in adaptation mechanisms' failure and weakening of organism's psycho-physiological reserves [12].

For the first time, we worked out and realized correction system for personal competence and readiness for RA intensification. It included purpose, tasks and the following sub-systems: components of physical recreation personal competence; program and stages of its realization; methods and methodic techniques; principles, criteria and results of assessment.

The worked out structural-logic model of program permitted to test assessment and its criteria for different levels of teachers' readiness for recreation activity's intensification. The model permitted to experimentally check the program effectiveness. Such program is directed at formation of personality's competences in respect of recreation-motor activity and sleep correction as a component of psycho-physiological condition of elderly age teachers. Implementation of such program significantly increases recreation activity; improves teachers' attitude to own psycho-physiological condition. The program permits to plan own functioning in intensification of recreation activity, facilitates somatic health improvement.

\section{Conclusions}

1. It was found that teachers' life quality is influenced by the following factors: age; motor activity; stress situations, connected with professional activity; recreation-motor activity in leisure time; chronic diseases. Social factors, influencing negatively on life quality, are: loneliness; absence of regular health related recreation measures; psycho-emotional overloads, conditioned by professional activity.

2. Positive changes took place in somatic health (in particular, quantity of teachers with average and above average somatic health level) and motor activity: quantity of persons with average and above average levels increased 2.1 times; confidently increased indicators of day physical activity index. Besides, indicators of body weight index reduced in $30.2 \%$ teachers.

3. Activation of physical recreation permitted to improve psycho-physiological condition in $42.1 \%$ men and $45.2 \%$ women. It is subjectively proved by the data of repeated questioning by complex of questions "Healthy sleep". This fact is registered objectively by the following: improvement of recreation coefficient (by the data of electro-cardio-intervalography); positive changes in main waves' amplitude-frequency characteristics (in $45.2 \%$ cases); sleep stabilization in $64.1 \%$ persons (by EEG data).

Further researches can be directed at improvement physical education system in conditions of industrial collectives for recreation activity's improvement.

\section{Conflict of interests}

The author declares that there is no conflict of interests.

\section{References}

1. Sibil' MG, Svishh JS, Voronin DM. Zastosuvannia ozdorovchikh sistem z elementami dikhal'noi gimnastiki dlia pokrashchennia iakosti zhittia osib tret'ogo viku [Application of health related systems with breathing gymnastic elements for improvement life quality of third age persons]. Slobozhans'kij naukovo-sportivnij visnik, 2013;5:139-142. (in Ukrainian)

2. Dovganik MS, Chichkan OA, Strel'chenko VV. Zmini v sercevo-sudinnij sistemi cholovikiv ta zhinok protiagom trivalikh zaniat' ozdorovchim bigom [Changes in cardiovascular system in men and women during long time practicing health-run]. Slobozhans'kij naukovo-sportivnij visnik, 2014;2:76-79. (in Ukrainian)

3. Iermakov SS, Cheslic'ka M, Pilevs'ka V. Problemi ta perspektivi doslidzhen' rukhovoi aktivnosti osib seredn'ogo ta starshogo viku [Problems and prospects of mature and elder age persons' motor activity researches]. Visnik Prikarpats'kogo universitetu, 2013;18:207-213. (in Ukrainian)

4. Kanishheva OP, Mulik VV. Teoretichni osnovi ocinki adaptacijnikh mozhlivostej organizmu [Theoretical principles of organism's adaptation potentials]. Slobozhans'kij naukovo-sportivnij visnik [Principles of organism's potentials assessment]. Slobozhans'kij naukovo-sportivnij visnik, 2010;4:39-44. (in Ukrainian)

5. Karpiuk IIu. Dinamika motivacijnikh upodoban' liudej pokhilogo viku shchodo fizichnoi kul'turi [Dynamic of elderly people's motivation for physical culture]. Pedagogics, psychology, medical-biological problems of physical training and sports, 2006;2:50-55. (in Ukrainian)

6. Korobejnikov GV, Korobejnikova LG, Kozina ZhL. Ocinka ta korekciia psikhofiziologichnikh staniv u sporti [Assessment and correction of psycho-physiological state in sports], Harkiv: HNPU; 2012. (in Ukrainian)

7. Lukjanchenko MI. Methodology of recreation in the structure of educational space. Pedagogics, psychology, medical-biological problems of physical training and sports, 2011;2:75-78.

8. Zaytsev VP, Manucharjan SV, Prusik Kr, Prusik K, Cieslicka M, Szark-Eckardt M.Methodology of physical recreation: problems, experience, recommendations. Pedagogics, psychology, medical-biological problems of physical training and sports, 2013;4:13-20. doi:10.6084/m9.figshare.693024

9. Myhalchuk T. The formation of the systems of wellness wallking classes for the elderly. Pedagogics, psychology, medical-biological problems of physical training and sports, 2011;4:115-117.

10.Mickan BM, Popel' SL, Mickan MA. Metodi doslidzhennia fizichnogo rozvitku, fizichnoi pidgotovlenosti, fizichnoi pracezdatnosti ta somatichnogo zdorov'ia liudej riznogo viku [Methods of physical condition, physical fitness, physical workability and somatic health study in different age people], Ivano-Frankivs'k: Plaj, 2000. (in Ukrainian)

11.Mytskan BM, Fedynyak NV. Justification revitalizing body 
of persons "third age" by means of physical education. Pedagogics, psychology, medical-biological problems of physical training and sports, 2014;10:18-23. doi:10.5281/ zenodo.10485

12.Mikheenko OI. Concretization of essence of the concept "health" as a methodological basis for the practice of healing the human body. Pedagogics, psychology, medical-biological problems of physical training and sports, 2013;2:42-46. doi:10.6084/m9.figshare.639257

13.Mitjukov VA, Tomashevsky NI, Simarova AV, Kirillov AN, Pisarenko PN, Jarosh AN, Jureva SJu, Gerasimova MA. Updating of a way of life: physical activity, the behavioural psychotherapy, a healthy food - main principles of the prevention of obesity and illnesses of the person. Pedagogics, psychology, medical-biological problems of physical training and sports, 2009;5:174-180.

14.Pristupa Y, Zhepka A, Vojceh L. Rekreaciia, iak social'nokul'turne iavishche, riznovid i rezul'tat diial'nosti [Recreation as cultural phenomenon, kinds and result of activity]. Pedagogics, psychology, medical-biological problems of physical training and sports, 2007;1:112-120.

15.Sorokina SA. Influence of employments physical exercises on age-dependent changes and rates of senescence of organism for women 30-50 years. Pedagogics, psychology, medical-biological problems of physical training and sports, 2010; 7:109-111.

16.Afanasyev VV, Martinov YA, Shishac'ka VI, Scherbachenko
VK. The Hypokinesia in Higher Educational Institutions. Pedagogics, psychology, medical-biological problems of physical training and sports, 2009; 1:7-10.

17.Yermakov SS, Apanasenko GL, Bondarenko TV, Prasol SD. Physical culture is a basic instrument of culture of health. Pedagogics, psychology, medical-biological problems of physical training and sports, 2010;11:31-33.

18.Shchekina NB. Pre-conditions of development of ideas about health and healthy way of life. Pedagogics, psychology, medical-biological problems of physical training and sports, 2012;1:125-128.

19.Fedorjuk A, Popel S. Efficiency of program of increase of recreation activity on quality of life of teachers of senior age. Visnik Pricrpatskogo universitetu, 2015;22: 3-9.

20.Prusik Katerina. Criteria of estimation of positive health level are in the long-term process of the health training of women of senior age. Pedagogics, psychology, medical-biological problems of physical training and sports, 2011;9:139-143.

21.Kostencka A, Szark-Eckardt M. The estimation of educational needs of physical education teachers in the light of the new educational program basis. Human Movement, 2010; 11(2): 200-210. doi:10.2478/v10038-010-0014-2

22.Robin J. Aging and health: effects of the sense of control. Science, 2012;233:1271-1276.

23.Robert HW, Hondzinski JM, Lee CM. Evidence of an association among age-related changes in physical, psychomotor and autonomic function. Age and Ageing, 2003;32:415-421.

Information about the authors:

Mytskan B.M.; http://orcid.org/0000-0002-5853-713X; bogomdan_21@mail.ru; Vasyl Stefanyk Precarpathian National University; 57 Shevchenko Str., Ivano-Frankivsk, 76018, Ukraine.

Cynarski W.; http://orcid.org/0000-0002-4059-3861; ela_cyn@wp.pl; University of Rzeszów; ul.Towarnickiego 3, Rzeszów, -35-959, Polska.

Fedoryuk A.V.; http://orcid.org/0000-0003-1440-3217; ofedorjuk@bk.ru; Ivano-Frankivsk National Medical University; Str. Galician, 2, Ivano-Frankivsk, 76018, Ukraine.

Popel' S.L.; http://orcid.org/0000-0001-9019-3966; serg_popel@mail.ru; Vasyl Stefanyk Precarpathian National University; 57 Shevchenko Str., Ivano-Frankivsk, 76018, Ukraine.

Mytskan T.S.; http://orcid.org/0000-0002-4164-2961; tania_mytskan@ukr.net; Vasyl Stefanyk Precarpathian National University; 57 Shevchenko Str., Ivano-Frankivsk, 76018, Ukraine.

Zemska N.O.; http://orcid.org/0000-0002-8169-9954; varvaryk_n@mail.ru; Vasyl Stefanyk Precarpathian National University; 57 Shevchenko Str., Ivano-Frankivsk, 76018, Ukraine.

Cite this article as: Mytskan B.M., Cynarski W., Fedoryuk A.V. 3, Popel' S.L., Mytskan T.S., Zemska N.O. Correction of elderly age people's psycho-physiological condition by recreation motor activity. Pedagogics, psychology, medical-biological problems of physical training and sports, 2017;1:41-45. doi:10.15561/18189172.2017.0107

The electronic version of this article is the complete one and can be found online at: http://www.sportpedagogy.org.ua/index.php/PPS/issue/archive

This is an Open Access article distributed under the terms of the Creative Commons Attribution License, which permits unrestricted use, distribution, and reproduction in any medium, provided the original work is properly cited (http://creativecommons.org/licenses/by/4.0/deed.en).

Received: 11.12.2016

Accepted: 28.12.2016; Published: 24.01.2017 